\title{
The effects of six-week slow, controlled breathing exercises on heart rate variability in physically active, healthy individuals
}

\author{
Cihan Erdem Sürücü ${ }^{1 \mathrm{ABD}}$, Sarp Güner ${ }^{1 \mathrm{BD}}$, Caner Cüce ${ }^{1 \mathrm{BC}}$, Dicle Aras ${ }^{1 \mathrm{CD}}$, Firat Akça ${ }^{1 \mathrm{CD}}$, Erşan Arslan ${ }^{2 \mathrm{D}}$, Abdulkadir
} Birol $^{1 \mathrm{D}}$, Alkan Uğurlu ${ }^{3 \mathrm{~B}}$

${ }^{1}$ Ankara University, Turkey

${ }^{2}$ Siirt University, Turkey

${ }^{3}$ Akdeniz University, Turkey

Authors' Contribution: A - Study design; B - Data collection; C - Statistical analysis; D - Manuscript Preparation; E - Funds Collection*

\begin{abstract}
Purpose: $\quad$ Heart rate variability (HRV) provides information about sympathetic-parasympathetic balance. The effects of different types of physical exercises on HRV have been investigated so far. The purpose of the current study was to evaluate the chronic effects of six-week slow and controlled breathing exercise on HRV in physically active, healthy adults.

Material: $\quad$ A total of 22 individuals (11 female, 11 male) participated in the study voluntarily. The experimental group (EG) attended to the breathing exercises for 15 minutes per day, three days a week for six weeks. Neither the EG nor the control group (CG) did join in any regular physical activity program during the study. Both groups participated in the HRV measurements before and after the six-week of process.

Results: $\quad$ Only the EG showed statistically significant changes in some HRV parameters. The alterations observed in LF:HF ratio, HFnu, and LFnu parameters were to reflect the increase in parasympathetic activity. Although the changes in the other parameters of HRV such as SDNN, SDSD, RMSSD, TP, HF, LF, and VLF were also related to increased vagal activity, these alterations were not significant. However, no significant change was found in the CG.

Conclusions: $\quad$ These results show that only the slow, controlled breathing exercises for six weeks could be used to improve parasympathetic activity in physically active individuals. A study could be designed where the duration is kept over 8 weeks, and the effects of physical exercises only, breathing exercises only, and physical + breathing exercises together on HRV are examined.

Keywords: heart rate variability, breathing exercise, autonomic nervous system
\end{abstract}

\section{Introduction}

Heart rate variability (HRV) can be defined as an electrocardiographic method which provides information about the both sympathetic and parasympathetic activity [1]. Due to the fact that autonomic nervous system (ANS) is considered as a marker of heart functions, and related to cardiovascular health, HRV has been widely used as a non-invasive method to evaluate the autonomic nervous system's functions $[2,3]$. In addition to the field of health sciences, HRV measurements are also used in sport and exercise sciences to monitor the recovery process after physical activities with different type and intensities [46]. The general expectation is to increase the effectiveness of parasympathetic activity both in health and sport and exercise sciences. In order to increase either acute or chronic vagal activity, several exercise or recovery methods have been implemented so far [6-9], and an improved HRV was found related to enhanced level of physical fitness $[10,11]$.

Alternatively, to the physical exercises, breathing exercises have also been utilized to enhance the activity of ANS. It was reported that breathing could be considered essential for life as well as for protection from diseases and to improve quality of life, health and energy balance

(c) Cihan Erdem Sürücü, Sarp Güner, Caner Cüce, Dicle Aras, Fırat Akça, Erşan Arslan, Abdulkadir Birol, Alkan Uğurlu., 2021

doi:10.15561/26649837.2021.0101
[12]. Therefore, some studies investigated the effect of breathing exercises in different groups in the literature. For instance, Pal et al. [13] found an improved vagal activity as a response to the three-month slow breathing exercise in young, healthy subjects. In another study, the acute effect of slow breathing exercises was caused increased vagal activity when compared fast breathing exercises [14]. The effects of slow breathing exercises were examined also in individuals with some diseases. Some of these studies reported that controlled or uncontrolled slow breathing exercises caused a decrease in blood pressure $[15,16]$, an improvement in pulmonary functions $[17,18]$, chronic insomnia [19, 20], chronic heart failure [21], and anxiety [22]. As slow breathing exercise is a non-pharmacological method, and easy to perform, it was frequently utilized to improve the autonomic regulation in individuals with different diseases by researchers.

When studies are examined, it can be understood that a high level of vagal tone is associated with a lower level of disease. This emphasizes that an improved HRV provides a better level of health, and slow breathing exercise is one of the methods to enhance the HRV [23]. Although slow breathing exercises have been studied with an increasing interest in recent years, the number of the studies examining the chronic effects of slow breathing on ANS in healthy individuals is still limited. Therefore, the aim 
of the present study was to investigate the chronic effects of six-week slow and controlled breathing exercises on the sympathetic and parasympathetic sub-branches of the autonomic nervous system in physically active, healthy adults. It was hypothesized that both time- and frequencydomain parameters of HRV would statistically change showing an increase in parasympathetic activity in the experimental group.

\section{Material and Methods}

\section{Participants}

A total number of twenty-two healthy subjects participated in the study voluntarily. They were randomly divided into the experimental and control groups. Individuals with lower level of physical activity, who do not perform at least $150 \mathrm{~min}$ of physical activity at the level of 3-6 MET per week, athletes, and individuals, having any diseases, excluded from the study. Similarly, people, who had respiratory problems up to six months before the study, were also excluded from the study. All participants were informed about the study design, were explained about the possible benefits and risks of the research and were also taught the correct diaphragmatic breathing, in the first meeting. After familiarization, all subjects were given a written informed consent form which was prepared according to the Declaration of Helsinki (code DoH-Oct2013). Table 1 demonstrates information about the participants.

Study design

This study was designed to evaluate the effects of six-week slow, controlled breathing exercises on HRV in physically active, healthy individuals. In order to achieve this aim, subjects were taught the correct diaphragmatic breathing, to inhale through the nose and exhale through the mouth, in the first, familiarization meeting. After that, participants, in the experimental group, visited the laboratory 3 days a week, for six week and attended to 15 min breathing exercise sessions. All subjects participated in the HRV measurements before starting the study and one day after the study ended.

Exercise protocol

The slow and controlled breathing exercises were performed in quiet room only by the experimental group. Breathing exercises were performed with 10 sec of diaphragmatic breathing cycles ( 6 breaths/min), including $5 \mathrm{sec}$ of inhalation and $5 \mathrm{sec}$ of exhalation, for 15 minutes per day, three days a week for six weeks. All the participants were in supine position one meter apart from each other during each breathing session, and they were asked not to move or speak during the exercise. To provide the subjects to easily track the $5 \mathrm{sec}$ of inhalation and $5 \mathrm{sec}$ of exhalation cycles, a large computer screen was projected on the ceiling showing the 5-sec time flow. This 15-min diaphragmatic breathing cycle was repeated 3 days a week with a minimum interval of one-day break for six weeks.

\section{HRV measurements}

The HRV measurements, before and after the six-week breathing exercise program, in both groups were performed in the performance laboratory in a quiet environment. The humidity of the laboratory was kept under $50 \%$, and the temperature between $20-22^{\circ} \mathrm{C}$ by using an air conditioner. All the data were collected between 3 to $5 \mathrm{pm}$ in two separate days. Subjects were asked to stop eating at least two hours prior to the measurements. They were also warned not to exercise, and not to consume alcohol within the 24 hours before the test, and to urinate within the $30 \mathrm{~min}$ before the test. Participants' caffeine intake was also limited within the previous 12 hours of the test. The data were obtained in supine position on a stretcher while the male participants were wearing only shorts and female participants shorts and sport bras. The HRV data were collected by using OmegaWave 800 (OW, Oregon, USA) device, and took each participant 5 minutes. Before the placement of three thoracic Wilson electrodes and four Limb electrodes subjects were told not to talk or move during the measurements, and after three min of resting phase the HRV recording was started. The parameters obtained from HRV recording were SDNN, SDSD, RMSSD, TP, HF, HFnu, LF, LFnu, and VLF.

Statistical analysis

All analyses were performed using the SPSS v.22 (SPSS Inc., Chicago, IL, USA). At first, the distribution of data was tested to determine if the test to be used for average comparison is parametric or not. Normality distribution was tested with Shapiro Wilk, as in both groups the number of participants was below 50. Average differences were determined with the parametric Paired Sample $t$-Test for the data where distribution is normal and with the nonparametric Wilcoxon Test for the data where distribution was not normal. An alpha value of 0.05 was accepted for all the statistical analyses.

\section{Results}

Table 2 represents the results of the tests performed before and after the six-week breathing exercises by the experimental group. According to the results it could be seen that the LF:HF ratio $(\mathrm{p}<0.01)$, HFnu and LFnu values

Table 1. Demographic information of the participants.

\begin{tabular}{lllll}
\hline Parameters & Age & $\begin{array}{l}\text { Body height } \\
\text { (cm) }\end{array}$ & $\begin{array}{l}\text { Body weight } \\
\text { (kg) }\end{array}$ & $\begin{array}{l}\text { Body mass } \\
\text { index }\end{array}$ \\
\hline Experimental Group (6 male, 5 female) & $21.36 \pm 1.56$ & $175.36 \pm 7.95$ & $66.63 \pm 11.83$ & $21.55 \pm 2.96$ \\
Control Group (5 male, 6 female) & $23.10 \pm 1.79$ & $169.60 \pm 6.70$ & $59.80 \pm 9.97$ & $21.66 \pm 3.28$ \\
\hline
\end{tabular}


$(\mathrm{p}<0.05)$ changed statistically. The percentage alteration in LF:HF ratio was $34.17 \%$, in HFnu $25.69 \%$, and LFnu $23.05 \%$. However, no statistically significant difference was found in SDNN, SDSD, RMSSD, TP, HF, LF, and VLF parameters in the experimental group.

Table 3 shows the results derived from the control group. When the findings, obtained from the control group, were examined, no statistically significant change was found in any of the HRV parameters.

\section{Discussion}

The present study aimed to understand the chronic effects of slow, controlled breathing exercises on HRV parameters in physically active, healthy individuals. Therefore, subjects participated in breathing exercises for 15 minutes per day, three days a week for six weeks. In accordance with the literature, respiratory rate was determined as six per minute [24]. Another substantial issue besides breathing rate was inhalation and exhalation time ratio (I:E ratio). Different types of $\mathrm{I}: \mathrm{E}$ ratios have been investigated to observe the changes in HRV so far. While some studies have found that breathing with short inhale followed by long exhale is tending to increase the vagal activity more when compared breathing with long inhale followed by short exhale $[25,26]$, the I:E ratio did not affect the effectiveness of vagal tone in some other research [27-29]. Thus, each diaphragmatic slow breath cycle was consisted of $5 \mathrm{sec}$ of inhale, and $5 \mathrm{sec}$ of exhale components in the current research.

According to the results, statistically significant changes were seen only in the experimental group. These frequency-domain parameters of HRV were LF:HF ratio, HFnu, and LFnu. LF:HF ratio showed $34.12 \%$ decrease $(p<0.01)$. The LF:HF ratio is considered one of the most important components of HRV, and it is defined as sympathovagal balance. The LF:HF ratio is expected 0 to 2 during the day, and increased LF:HF ratio is associated with sympathetic activity. Thus, observing $34.12 \%$ decrease in LF:HF ratio in the present study could be explained with increased vagal tone. Similarly to LF:HF ratio, LFnu is also evaluated as a marker of both sympathetic and vagal activity. Therefore, decreased LFnu (23.05\%) could be related to the increased parasympathetic effect after six weeks of slow, controlled breathing exercises $(p<0.05)$

Table 2. HRV results of the experimental group.

\begin{tabular}{lllll}
\hline Parameters & Pre-test & Post-test & $\boldsymbol{P}$ & Change (\%) \\
\hline SDNN & $43.27 \pm 17.51$ & $50.55 \pm 19.56$ & 0.299 & +16.82 \\
SDSD & $51.45 \pm 33.60$ & $58.36 \pm 34.88$ & 0.581 & +13.43 \\
RMSSD & $40.09 \pm 26.22$ & $46.00 \pm 27.44$ & 0.683 & +14.74 \\
TP & $745.73 \pm 656.35$ & $1021.64 \pm 847.56$ & 0.657 & +37.00 \\
LF:HF & $1.26 \pm 0.62$ & $0.83 \pm 0.71$ & $0.007 * *$ & -34.12 \\
HF & $365.64 \pm 441.20$ & $694.45 \pm 697.53$ & 0.213 & +89.92 \\
HFnu & $47.29 \pm 12.66$ & $59.44 \pm 20.23$ & $0.024 *$ & +25.69 \\
LF & $317.18 \pm 229.49$ & $267.91 \pm 183.37$ & 0.534 & -15.26 \\
LFnu & $52.71 \pm 12.66$ & $40.56 \pm 20.23$ & $0.024 *$ & -23.05 \\
VLF & $64.00 \pm 37.53$ & $58.82 \pm 21.37$ & 0.766 & -8.09 \\
\hline
\end{tabular}

SDNN: standard deviation of all NN intervals; SDSD: standard deviation of the successive differences between adjacent NN intervals; RMSSD: square root of the mean of the sum of the squares of differences between adjacent NN interval; TP: total power [ULF+VLF+LF+HF (>0.4 Hz)]; LF:HF: ratio of LF-to-HF power; HF: absolute power of the high-frequency band (0.15-0.4 Hz); HFnu: normalized HF spectral power; LF: absolute power of the low-frequency band $(0.04-0.15 \mathrm{~Hz})$; LFnu: normalized LF spectral power; VLF: absolute power of the very-low-frequency band $(0.0033-0.04 \mathrm{~Hz}) .^{*} \mathrm{p}<0.05$; $* * p<0.01$

Table 3. HRV results of the control group.

\begin{tabular}{lllll}
\hline Parameters & Pre-test & Post-test & $\boldsymbol{P}$ & Change (\%) \\
\hline SDNN & $72.09 \pm 26.30$ & $71.73 \pm 34.96$ & 0.945 & -0.50 \\
SDSD & $102.73 \pm 44.56$ & $95.64 \pm 65.89$ & 0.606 & -6.90 \\
RMSSD & $81.27 \pm 35.74$ & $74.91 \pm 51.63$ & 0.547 & -7.82 \\
TP & $2283.73 \pm 1722.94$ & $2236.00 \pm 2227.73$ & 0.110 & -2.09 \\
LF:HF & $0.75 \pm 0.67$ & $0.78 \pm 0.54$ & 0.656 & +4 \\
HF & $1324.82 \pm 1040.69$ & $1322.09 \pm 1558.88$ & 0.286 & -0.20 \\
HFnu & $63.20 \pm 17.61$ & $59.89 \pm 13.82$ & 0.607 & -5.23 \\
LF & $836.91 \pm 893.79$ & $777.82 \pm 747.30$ & 0.722 & -7.06 \\
LFnu & $36.80 \pm 17.61$ & $40.11 \pm 13.82$ & 0.607 & +8.99 \\
VLF & $122.00 \pm 69.71$ & $136.09 \pm 107.30$ & 0.604 & +11.55 \\
\hline
\end{tabular}

SDNN: standard deviation of all NN intervals; SDSD: standard deviation of the successive differences between adjacent NN intervals; RMSSD: square root of the mean of the sum of the squares of differences between adjacent NN interval; TP: total power [ULF+VLF+LF+HF (>0.4 Hz)]; LF:HF: ratio of LF-to-HF power; HF: absolute power of the high-frequency band (0.15-0.4 Hz); HFnu: normalized HF spectral power; LF: absolute power of the low-frequency band $(0.04-0.15 \mathrm{~Hz})$; LFnu: normalized LF spectral power; VLF: absolute power of the very-low-frequency band $(0.0033-0.04 \mathrm{~Hz})$. $^{*} \mathrm{p}<0.05$; $* * p<0.01$ 
when the changes in LF:HF and HFnu are taken into account [30]. Another finding showing improved vagal activity was HFnu with an increase of $25.69 \%(\mathrm{p}<0.05)$. Other frequency-domain parameters TP $(+37 \%)$, HF (+ $89.92 \%)$, LF (- $15.26 \%$ ), and VLF (- $8.09 \%$ ) did not show significant alterations. Although, the changes in time-domain parameters were also related to improved vagal activity, these were not statistically significant, contrary to the hypothesis. The SDNN (16.82\%), SDSD $(13.43 \%)$, and RMSSD (14.74\%) increased after the sixweek breathing exercises. Therefore, the duration of the study may be planned longer than six weeks in the future studies. In spite of the changes observed in experimental group, no significant change was observed in any HRV parameters in the control group.

There are number of studies in the literature which investigated chronic effects of different paced breathing exercises on individuals with chronic diseases. Das and Ferdousi [31] found increment in resting heart rate, short and long term SDRR values of HRV after threemonth slow breathing exercises in transfusion dependent thalassaemic patients. Mourya et al. [32] compared the three-month slow and fast breathing exercises on autonomic functions in patients with stage one essential hypertension, and reported that slow breathing was more correlated with an improved ANS activity. Again, after a three-month slow breathing exercises the average heart rate, mean RR intervals, SDNN, and RMS values of HRV measurement showed a significant improvement in patients with type 2 diabetes mellitus [33]. Since respiratory functions are highly correlated with HRV, and strengthening the respiratory muscles that help breathing [34] is considered as a result of breathing exercises, Han and Kim [17] investigated the effects of four-week breathing exercises combined with upper body exercises in adults. They found that both combined breathing and upper body training, and only breathing training caused significant increases in forced vital capacity (FVC) $(\mathrm{p}<0.05)$, and the forced expiratory volume $(\mathrm{FEV})$ value was higher in combined training group. In a similar study it was found that three-month slow breathing exercises are more effective in some pulmonary functions such as FVC, $\mathrm{FEV}_{1}$, and $\mathrm{FEV}_{1} / \mathrm{FVC}$ in patients with major depressive disorder [18]. Kawecka Jaszcz et al. [21] found significant changes in physical exercise capacity, ejection fraction, and also sleep disorders after slow breathing exercises performed in patients with chronic heart failure with a frequency of 6 breaths per minute for three months. Zou et al. [35] stated in their meta-analysis that slow breathing could reduce the resting heart rate, and systolic and diastolic blood pressure in patients with cardiovascular diseases.

The chronic effects of slow breathing exercises in healthy individuals have also been examined in a limited number of studies. In some of them it was stated that activities such as yoga, involving slow breathing sessions named pranayama, can help to control and enhance the ANS by improving the parasympathetic activity [3638]. Turankar et al. [39] pointed that slow, controlled breathing exercise during the pranayama phase for 20 minutes, twice a day for 7 days decrease resting HR, and sympathetic tone of the ANS. Each breathing cycle consisted of $6 \mathrm{sec}$ inhales through the left nostril, $6 \mathrm{sec}$ of hold and $6 \mathrm{sec}$ of exhale through the right nostril. These changes, occurred only in 7 days, were observed in healthy male and female individuals. Another study which was performed in healthy adults showed that slow and controlled yoga breathing exercises five days a week for six months provides positive alterations in cardiac autonomic modulation by increasing the parasympathetic activity [40]. Each breathing session consisted of 5 cycles for 5 times with $2 \mathrm{~min}$ of resting intervals, and subjects did 3-6 breath/min during the whole implementation. Authors recorded significant changes in resting heart rate, SDNN, RMSSD, NN50, pNN50, Lfnu, Hfnu, and LF:HF ratio. In Tharion et al.'s study [41], healthy participants performed breathing exercises at a rate of 6 breaths per minute (4 sec of inspiration, and $6 \mathrm{sec}$ of expiration time) for half an hour a day for one month, and statistically significant changes in HF power, $\mathrm{LF}+\mathrm{HF}$ power, arterial blood pressure, and respiratory rate in the experimental group were found while it was reported no change in the control group. The findings of the above-mentioned studies are in line with the results of the current research. Accordingly, it can be seen that slow breathing exercises in different cycles reveal significant changes in different parameters of HRV.

As a result, the present study proved that slow and controlled breathing exercises provide enhancement in parasympathetic activity in physically active, healthy adults. When positive effects of an improved autonomic nervous system taken into account, this type of exercise could be recommended for healthy adults to improve their heart functions. Since HRV is highly correlated with cardiovascular and metabolic diseases, this could reduce the risk of prevalence to fatal diseases [23]. In addition, athletes can benefit from slow and controlled breathing exercises. When a rapid recovery in heart functions is aimed, athletes could implement slow breathing exercises at the end of a training session, especially after a vigorous physical activity. This would help with speeding up the recovery process. The duration of the study might be planned for more than six weeks or the number of slow and controlled breathing exercise sessions could be increased in future studies, since the substantial improvements observed in time-domain parameters were not significant in the current research. Future studies could also compare the effectiveness of physical and breathing exercises on HRV simultaneously, by adding a physical exercise group, a breathing exercise group, a physical + breathing exercise group, and a control group.

\section{Financial support*}

There is no financial support for the present study.

\section{Conflict of interest}

The authors declare no conflict of interest. 


\section{References}

1. Sztajzel J. Heart rate variability: a noninvasive electrocardiographic method to measure the autonomic nervous system. Swiss Med Wkly. 2004;134:514-522.

2. Myllymaki T, Rusko H, Syvaoja H, Juuti T, Kinnunen ML, Kyrolainen $H$. Effects of exercise intensity and duration on nocturnal heart rate variability and sleep quality. Eur $J$ Appl Physiol. 2012;112:801-809. https://doi.org/10.1007/s00421-011-2034-9

3. Grieco CR, Colberg SR, Somma CT, Thompsan AG, Vinik AI. Acute effect of breathing exercises on heart rate variability in type 2 diabetes: a pilot study. $J$ Altern Complement Med. 2014;20(8):642-648. https://doi.org/10.1089/acm.2013.0280

4. Borresan J, Lambert MI. Autonomic control of heart rate during and after exercise. Sports Med. 2008;38(8):633-646. https://doi.org/10.2165/00007256-200838080-00002

5. Saboul D, Pialoux V, Hautier C. The breathing effect of the $\mathrm{LF} / \mathrm{HF}$ ratio in the heart rate variability measurements of athletes. Eur J Sport Sci. 2014;14(sup1):S282-S288. https://doi.org/10.1080/17461391.2012.691116

6. Aras D, Akalan C, Koz M, İleri M. Does long term sport rock climbing training affect on echocardiography and heart rate variability in sedentary adults? A randomized, and controlled study. J Appl Exerc Physiol. 2016;5(1):26-31.

7. Telles S, Raghavendra BR, Naveen KV, Manjunath NK, Kumar S, Subramanya P. Changes in autonomic variables following two meditative states described in yoga texts. J Altern Complement Med. 2013;19:35-42. https://doi.org/10.1089/acm.2011.0282

8. Ostariz ES, Ramon ML, Arroyos DC, Alvares SI, Edo PC, Sahun $\mathrm{CB}$, et al. Post-exercise left ventricular dysfunction measured after a long-duration cycling event. BMC Res Notes. 2013;6(211):1-5. https://doi.org/10.1186/1756-0500-6-211

9. Aras D, Karakoc B, Koz M, Bizati O. The effects active recovery and carbohydrate intake on HRV during 48 hours in athletes after a vigorous-intensity physical activity. Sci Sports. 2017;32:295-302. https://doi.org/10.1016/j.scispo.2017.04.010

10.Aubert AE, Seps B, Beckers F. Heart rate variability in athletes. Sports Med. 2003;33:889-919. https://doi.org/10.2165/00007256-200333120-00003

11. Williams S, Booton T, Watson M, Rowland D, Altini M. Heart Rate Variability is a moderating factor in the workloadinjury relationship of competitive CrossFitt athletes. J Sports Sci Med. 2017;16:443-449.

12.Edwards SD. A psychology of breathing methods. Int $J$ Ment Health Promot. 2005;7(4):30-36. https://doi.org/10.1080/14623730.2005.9721958

13.Pal GK, Velkumary S, Madanmohan. Effect of short-term practice of breathing exercises on autonomic functions in normal human volunteers. Indian J Med Res. 2004;120:115121.

14.Sakakibara M, Hayano J. Effect of slowed respiration on cardiac parasympathetic response to threat. Psychosom Med. 1996;58:32-37.

15.Meles E, Giannattasio C, Failla M, Gentile G, Capra A, Mancia G. Nonpharmacologic treatment of hypertension by respiratory exercise in the home setting. Am J Hypertens. 2004;17:370-374. https://doi.org/10.1016/j.amjhyper.2003.12.009

16.JonesCU, Sangthog B, PachiratO.Aninspiratoryloadenhances the antihypertensive effects of home-based training with slow breathing: a randomised trial. J Physiother. 2010;56:179-186. https://doi.org/10.1016/S1836-9553(10)70023-0
17.Han JW, Kim YM. Effect of breathing exercises combined with dynamic upper- extremity exercises on the pulmonary function of young adults. $J$ Back Musculoskelet Rehabil. 2018;31:405-409. https://doi.org/10.3233/BMR-170823

18.Ferdousi S, Afreen KN, Algin S. effect of slow breathing exercise on forced vital capacity and forced expiratory volume in patients with major depressive disorder. Bangladesh Med Res Counc Bull. 2018;44:118-123. https://doi.org/10.3329/bmrcb.v44i3.39934

19.Khalsa SB. Treatment of chronic insomnia with yoga: a preliminary study with sleep-wake diaries. Appl Psychophysiol Biofeedback. 2004;29(4):269-278. https://doi.org/10.1007/s10484-004-0387-0

20.Tsai HJ, Kuo TBJ, Lee GS, Young CCH. Efficacy of paced breathing for insomnia: Enhances vagal activity and improves sleep quality. Psychophysiology. 2015;52:388-396. https://doi.org/10.1111/psyp.12333

21.Kawecka Jaszcz K, Bilo G, Drozdz T, Debicka Dabrowska D, Kielbasa G, Malfatto G, et al. Effects of device guided slow breathing training on exercise capacity, cardiac function, and respiratory patterns during sleep in male and female patients with chronic heart failure. Pol Arch Intern Med. 2017;127(1):8-15. https://doi.org/10.20452/pamw.3890

22.Sellakumar GK. Effect of slow-deep breathing exercise to reduce anxiety among adolescent school students in a selected higher secondary school in Coimbatore. India. $J$ Psychol Educ Res. 2015;23(1):54-72.

23.Yuen AWC, Sander JW. Can slow breathing exercises improve seizure control in people with refractory epilepsy? A hypothesis. Epilepsy Behav. 2010;18:331-334. https://doi.org/10.1016/j.yebeh.2010.05.019

24.Hayano J, Mukai S, Sakakibara M, Okada A, Takata K, Fujinami T. Effects of respiratory interval on vagal modulation of heart rate. Am $J$ Physiol. 1994;267(1 Pt 2):33-40. https://doi.org/10.1152/ajpheart.1994.267.1.H33

25.Strauss-Blasche G, Moser M, Voica M, McLeod DR, Klammer N, Marktl W. Relative timing of inspiration and expiration affects respiratory sinus arrhythmia. Clin Exp Pharmacol Physiol. 2000;27:601-606. https://doi.org/10.1046/j.1440-1681.2000.03306.x

26.Van Diest I, Verstappen K, Aubert AE, Widjaja D, Vansteenwegen D, Vlemincx E. Inhalation/exhalation ratio modulates the effect of slow breathing on heart rate variability and relaxation. Appl Psychophysiol Biofeedback. 2014;39(3-4):171-80.

27.Klintworth A, Ajtay Z, Paljunite A, Szabados S, Hejjel L. Heart rate asymmetry follows the inspiration/expiration ratio in healthy volunteers. Physiol Meas. 2012;33(10):1717-1731. https://doi.org/10.1088/0967-3334/33/10/1717

28.Wang YP, Kuo TB, Lai CT, Chu JW, Yang CC. Effects of respiratory time ratio on heart rate variability and spontaneous baroreflex sensitivity. J Appl Physiol. 2013;115(11):1648-1655. https://doi.org/10.1152/japplphysiol.00163.2013

29. De Couck M, Caers R, Musch L, Fliegauf J, Giangreco A, Gidron Y. How breathing can help you make better decisions: Two studies on the effects of breathing patterns on heart rate variability and decision-making in business cases. Int $J$ Psychophysiol. 2019;139:1-9. https://doi.org/10.1016/j.ijpsycho.2019.02.011

30.Burr RL. Interpretation of normalized spectral heart rate variability indices in sleep research: a critical review. Sleep. 2007;30(7):913-919. https://doi.org/10.1093/sleep/30.7.913 
31.Das KC, Ferdousi S. Effect of slow breathing exercise on nonlinearheartratevariabilityintransfusiondependent thalassemic patients. J Bangladesh Soc Physiol. 2019;14(1):26-32. https://doi.org/10.3329/jbsp.v14i1.41998

32. Mourya M, Mahajan AS, Singh NP, Jain AK. Effect of slow- fast breathing exercises on autonomic functions in patients with essential hypertension. $J$ Altern Complement Med. 2009;15(7):711-717. https://doi.org/10.1089/acm.2008.0609

33.Yesmin J, Begum N, Ferdousi S. Effect on time domain parameters of HRV after slow breathing exercise in type 2 diabetesmellitus.JBangladeshSocPhysiol.2017;12(1):15-20. https://doi.org/10.3329/jbsp.v12i1.33923

34.Lee J, Kwon Y, Kim K. The effect of chest expansion and pulmonary function of stroke patients after breathing exercise. J Korean Phys Ther. 2009:21(3):25-32.

35.Zou Y, Zhao X, Hou YY, Liu TWQ, Huang YH, Wang WH. Meta-analysis of effects of voluntary slow breathing exercises for control of heart rate and blood pressure in patients with cardiovascular diseases. Am J Cardiol. 2017;120:148-153. https://doi.org/10.1016/j.amjcard.2017.03.247

36.Jerath R, Edry JW, Barnes VA, Jerath V. Physiology of long pranayamic breathing: Neural respiratory elements may provide a mechanism that explains how slow deep breathing shifts the autonomic nervous system. Med Hypotheses. 2006;67:566-571. https://doi.org/10.1016/j.mehy.2006.02.042

37.Dhungel KU, Malhotra V, Sarkar D, Parajapati R. Effect of alternate nostril breathing exercise on cardiorespiratory functions. Nepal Med Coll J. 2008;10:25-27.

38.Tyagi A, Cohen M. Yoga and heart rate variability: A comprehensive review of the literature. Int $J$ Yoga. 2016;9:97-113. https://doi.org/10.4103/0973-6131.183712

39.Turankar AV, Jain S, Patel SB, Sinha SR, Joshi AD, Vallish $\mathrm{BN}$, et al. Effects of slow breathing exercise on cardiovascular functions, pulmonary functions \& galvanic skin resistance in healthy human volunteers-a pilot study. Indian J Med Res. 2013;137(5):916.

40.Kuppusamy M, Kamaldeen D, Pitani R, Amaldas J, Ramasamy P, Shanmugam P, et al. Effects of yoga breathing practice on heart rate variability in healthy adolescents: a randomized controlled trial. Integr Med Res. 2020;9(1):28-32. https://doi.org/10.1016/j.imr.2020.01.006

41.Tharion E, Samuel P, Rajalakshmi R, Gnanasenthil G, Subramanian RK. Influence of deep breathing exercise on spontaneous respiratory rate and heart rate variability: a randomised controlled trial in healthy subjects. Indian $J$ Physiol Pharmacol. 2012;56(1):80-87.

\section{Information about the authors:}

Cihan Erdem Sürücü; https://orcid.org/0000-0001-8193-9842; cihanerdemsurucu@gmail.com; Faculty of Sport Sciences, Undergraduate Education, Ankara University; Ankara, Turkey.

Sarp Güner; https://orcid.org/0000-0002-3483-544X; gunersarp@gmail.com; Faculty of Sport Sciences, Undergraduate Education, Ankara University; Ankara, Turkey.

Caner Cüce; https://orcid.org/0000-0001-8508-8774; yucecaner7@gmail.com; Faculty of Sport Sciences, Undergraduate Education, Ankara University; Ankara, Turkey.

Dicle Aras; (Corresponding Author); https://orcid.org/0000-0002-9443-9860; diclearasx@gmil.com; Faculty of Sport Sciences, Department of Coaching Education, Ankara University; Ankara, Turkey.

Fırat Akça; https://orcid.org/0000-0002-0764-105X; firatakca@gmail.com; Faculty of Sport Sciences, Department of Coaching Education, Ankara University; Ankara, Turkey.

Erşan Arslan; https://orcid.org/0000-0002-2933-6937; ersanarslan1980@hotmail.com; School of Physical Education and Sports, Department of Coaching Education, Siirt University; Siirt, Turkey.

Abdulkadir Birol; https://orcid.org/0000-0002-3312-9746; birol_kadir@hotmail.com; Graduate School of Health Sciences, Sport Sciences, Ankara University; Ankara, Turkey.

Alkan Uğurlu; https://orcid.org/0000-0002-4828-6285; alkanu@gmail.com; Faculty of Sport Sciences, Department of Physical Education and Sports, Akdeniz University; Ankara, Turkey.

Cite this article as:

Sürücü CE, Güner S, Cüce C, Aras D, Akça F, Arslan E, Birol A, Uğurlu. A The effects of six-week slow, controlled breathing exercises on heart rate variability in physically active, healthy individuals. Pedagogy of Physical Culture and Sports, 2021;25(1):4-9.

https://doi.org/10.15561/26649837.2021.0101

This is an Open Access article distributed under the terms of the Creative Commons Attribution License, which permits unrestricted use, distribution, and reproduction in any medium, provided the original work is properly cited (http://creativecommons.org/licenses/by/4.0/deed.en).

Received: 20.06.2020

Accepted: 02.08.2020; Published: 25.02.2021 